\title{
Chronos Ações: Ferramenta para Apoiar a Tomada de Decisão de Investidores da Bolsa de Valores
}

\section{Alternative title: Chronos Ações: Tool to Support Decision Making for Investor of the Stock Exchange}

\author{
Tibério César Souza do Nascimento \\ Instituto Metrópole Digital \\ Universidade Federal do Rio Grande do Norte (UFRN) \\ Natal, RN, 59078-970, Brasil \\ tiberiocsdn@gmail.com
}

\author{
Leonardo Cunha de Miranda \\ Departamento de Informática e Matemática Aplicada \\ Universidade Federal do Rio Grande do Norte (UFRN) \\ Natal, RN, 59078-970, Brasil \\ leonardo@dimap.ufrn.br
}

\begin{abstract}
RESUMO
Os investidores no mercado de ações empregam diversas técnicas de análise gráfica para auxiliar na tomada de decisão acerca dos seus investimentos. Para facilitar o uso dessas técnicas são desenvolvidas ferramentas capazes de processar grandes volumes de dados com o intuito de apresentar informações consolidadas para os investidores. Porém, a maioria dessas ferramentas é complexa de usar para quem está iniciando nesse tipo de mercado e, portanto, precisa de ajuda para tomar decisões mais embasadas visando minimizar os prejuízos e, ao mesmo tempo, maximizar os lucros. Nesse contexto, o presente trabalho apresenta o Chronos Ações, uma ferramenta desenvolvida para apoiar investidores na tomada de decisão de compra/venda de ações na BM\&FBOVESPA, que é a principal bolsa de valores do Brasil.
\end{abstract}

\section{Palavras-Chave}

BM\&FBOVESPA, Bovespa, mercado de ações, ativos.

\begin{abstract}
Investors in the stock market employ various techniques of graphical analysis to assist in decision making about their investments. To facilitate the use of these techniques are developed tools able to process large volumes of data in order to present consolidated information to investors. However, most of these tools is complex to use for those who are beginners in this kind of market and therefore needs help to make more informed decisions to minimize the damage and maximize profits at the same time. In this context, this work presents the Chronos Ações, a tool developed to support investors in making decision to purchasing or sale of assets on the BM\&FBOVESPA, which is the main stock exchange of Brazil.
\end{abstract}

\section{Categories and Subject Descriptors}

K.3.3 [Management of Computing and Information Systems]: Software Management - software development.

Permission to make digital or hard copies of all or part of this work for personal or classroom use is granted without fee provided that copies are not made or distributed for profit or commercial advantage and that copies bear this notice and the full citation on the first page. To copy otherwise, or republish, to post on servers or to redistribute to lists, requires prior specific permission and/or a fee.

SBSI 2015, May 26-29, 2015, Goiânia, Goiás, Brazil.

Copyright SBC 2015

\section{General Terms}

Design, Economics.

\section{Keywords}

BM\&FBOVESPA, Bovespa, stock market, assets.

\section{INTRODUÇ̃̃̃O}

O mundo conta com cerca de sete bilhões de pessoas e, no momento, a Internet já possui cerca de três bilhões de usuários [3]. Esse dado se configura como um dos indicadores da importância da Internet no dia a dia das pessoas, seja para o uso no trabalho ou lazer. Tomada como umas das maiores invenções da humanidade do século XX, a Internet influência diversos ramos na sociedade, tais como educação, saúde e negócios com impacto, inclusive, na forma como as pessoas lidam e operam com as suas finanças.

$\mathrm{Na}$ esfera financeira, a Internet proporciona a seus usuários acesso à internet banking, o uso de moedas virtuais - e.g. BitCoin - e notícias financeiras. Os bancos estão cada vez mais incorporando novos serviços de investimento aos seus sistemas, tais como, poupança, letra de crédito imobiliário, tesouro nacional, fundos de investimentos e mercado de ações. Nesse contexto, o investimento em mercado de ações acaba ficando mais acessível para os usuários e com isso ganhando destaque pela possibilidade de apresentar uma rentabilidade maior do que a de outros investimentos.

Para investir no mercado de ações, realizando operações de compra/venda de ações de companhias abertas, é necessário ter um cadastro em uma corretora que, por sua vez, deve estar autorizada pela Comissão de Valores Mobiliários (CVM) a executar operações de compra e venda de ações dos clientesinvestidores na bolsa de valores. Segundo [1], "as bolsas de valores são ambientes organizados para negociação de títulos e valores mobiliários. Sua principal função é proporcionar um ambiente mais líquido, transparente e seguro para a realização de negócios, contribuindo assim para a eficiência do mercado de capitais". As principais bolsas de valores do mundo, atualmente, são: NASDAQ, Bolsa de Valores de Nova Iorque (NYSE), Bolsa de Valores de Tokyo (TSE) e a Euronext. Com a criação da Lei $n^{\circ}$ 317, em 21 de outubro de 1843, foi instituída a primeira Bolsa de Valores do Rio de Janeiro quando o Imperador do Brasil, Dom Pedro II, regulamentou a profissão de corretor [11]. Hoje a principal bolsa de valores no Brasil é a BM\&FBOVESPA, que foi 
criada em maio de 2008, com a fusão da BM\&F Bolsa de Mercadorias \& Futuros e a Bolsa de Valores de São Paulo (BOVESPA). Assim, a BM\&FBOVESPA se tornou a maior bolsa da América Latina.

As ações - também chamadas de papéis ou ativos - no mercado de capitais representam uma pequena parte do capital social de uma empresa. Segundo [2], "ao comprar uma ação o investidor se torna sócio da empresa que emitiu essa ação, passando a correr os riscos dos negócios junto com a empresa e tendo participação nos lucros e prejuízos da mesma". Para se conseguir uma boa rentabilidade investindo em ações é necessário possuir um bom conhecimento da atual situação financeira da empresa que se quer investir, qual a sua prospecção para o futuro, e efetuar análises técnicas do histórico de informações daquela empresa na bolsa de valores.

Atualmente, existem diversas ferramentas que auxiliam investidores na tomada de decisão de seus investimentos. Contudo, boa parte das ferramentas mais robustas não são gratuitas. Geralmente essas ferramentas também apresentam limitações em relação ao seu uso em múltiplas plataformas - e.g. desktop, mobile e web -, onde algumas não conseguem, por exemplo, apresentar gráficos em dispositivos móveis, devido ao uso de tecnologias hoje consideradas obsoletas. Nesse contexto, este trabalho apresenta uma ferramenta desenvolvida para fornecer informações de fácil acesso para as pessoas que desejam investir na bolsa de valores BM\&FBOVESPA, mas que não possuem muito tempo para acompanhar diariamente o mercado e a bolsa de valores.

Este trabalho está organizado da seguinte maneira: a Seção 2 descreve as ferramentas relacionadas; a Seção 3 apresenta a ferramenta desenvolvida; a Seção 4 discute os resultados do trabalho; e a Seção 5 apresenta a conclusão.

\section{FERRAMENTAS RELACIONADAS}

Ferramentas que auxiliam investidores na tomada decisão estão presentes em diversas plataformas. Algumas relacionadas com este trabalho serão apresentadas a seguir, e foram selecionadas por serem alguns dos principais portais de provimento de informações e de utilização por parte dos investidores, tanto para visualização como para troca de informações por meio de fóruns de discussão. Assim, destacamos a seguir algumas das principais ferramentas gratuitas utilizadas por investidores brasileiros.

A Infomoney ${ }^{1}$ é um portal que apresenta informações do intraday $^{2}$ em forma de gráfico que é atualizado a cada 15 minutos. Também possui uma parte de análise técnica, que conta com um gráfico com a opção de selecionar quatro tipos de gráficos - i.e. linha, barra, Candlestick ${ }^{3}$ e área - com informações sobre o fechamento do ativo selecionado. A informação sobre o volume é dada em um gráfico do tipo barra e segue o mesmo período do gráfico do fechamento. $\mathrm{O}$ período máximo para a análise de informações é de três anos. Ainda conta com alguns

\footnotetext{
${ }^{1} \mathrm{http} / /$ www.infomoney.com.br.

2 Termo utilizado para negociações realizadas, no mesmo dia, entre a abertura do mercado e o seu fechamento.

3 Termo em inglês que significa "candelabro" por apresentar um formato parecido e possuir um "pavio" na parte superior e inferior do corpo.
}

tipos de indicadores como o Bollingner Bands ${ }^{4}$, MME $12 \mathrm{D}^{5}$ e o MME $26 D^{6}$. A tecnologia empregada para a exibição e interação com o gráfico é o Adobe Flash. O portal ainda conta com uma funcionalidade de sobreposição de gráficos entre ativos.

A $\mathbf{A D V F N}^{7}$ é uma ferramenta que funciona em várias plataformas, i.e., desktop, mobile e web. Na web, ela dispõe de dois tipos de tecnologias para construção de gráficos, um em Java Applet e outro em HTML5 (ainda na versão beta). O gráfico gerado, apresenta um período máximo de cinco anos, alguns tipos de indicadores para serem plotados e disponibiliza uma caixa de ferramentas para o investidor desenhar análises pelo gráfico, como linhas de suporte e resistência, e não apresenta gráfico sobre volume. A ferramenta apresenta seis tipos de gráficos. Assim, além dos quatro tipos existentes na ferramenta da Infomoney (i.e. linha, barra, Candlestick e áreas), possui também os gráficos Heiken Ashi e Vela transparente, que são variações do Candlestick. Essa ferramenta, ainda, conta com a opção de alarme por preço do ativo. A ADVFN possui análises técnicas mais profundas, mas são pagas, como análise de padrões de CandleStick, suporte e resistência, figuras de reversão e indicadores de preço.

A própria BM\&FBOVESPA ${ }^{8}$ apresenta opções para que o investidor possa analisar informações de ativos em um gráfico com um período máximo de um ano. Essa ferramenta permite a sobreposição de informações entre ativos no gráfico, e mostra informações sobre abertura, fechamento, máximo, mínimo, oscilação e a média. O gráfico de cotação não possui estudo de índices, e a tecnologia usada é HTML5. Na página principal do pregão online, tem informações sobre as cinco maiores altas, as cinco maiores baixas e os cincos maiores papéis negociados no último pregão. O site também provê informações dos pregões na forma de dados bruta e pré-compilada por anos ou meses. Seu aplicativo mobile possui informações do intraday, além de opções para criação de carteira e visualização de informações dos indicadores de desempenho de um conjunto de ações no último pregão.

O UOL Economia ${ }^{9}$ apresenta três tipos de gráficos - i.e. área, Candlestick e $\mathrm{OHLC}^{10}-$, e permite que o usuário selecione datas predefinidas - e.g. um dia, uma semana, um mês, três meses ou um ano - além de permitir a seleção customizada das datas. No entanto, essa ferramenta só mostra dados a partir de 2006, e não possui informação gráfica sobre volume ou quantidade de negociações. $\mathrm{O}$ Yahoo Finanças $^{11}$ fornece informações detalhadas a respeito de ativos, como a visualização do intraday, notícias e informações da empresa. As análises técnicas ficam por conta de um gráfico interativo feito em Flash, e conta com os mesmos quatro tipos de gráficos da Infomoney. Também possui

\footnotetext{
4 Análise usada para medir a flutuação do preço da ação em relação a preços anteriores.

${ }^{5}$ Média Móvel Exponencial de 12 dias. O objetivo principal é acompanhar a mudança de preço de uma ação, utilizando uma fórmula definida para o cálculo de 12 dias.

${ }^{6}$ Média Móvel Exponencial de 26 dias.

${ }^{7} \mathrm{http}: / /$ br.advfn.com.

${ }^{8} \mathrm{http}: / /$ www.bmfbovespa.com.br.

${ }^{9} \mathrm{http} / / /$ economia.uol.com.br/cotacoes/bolsas/

10 Acrônimo de Open High Low Close, que é um gráfico semelhante ao Candlestick, porém que não apresenta o corpo.

${ }^{11} \mathrm{http}$ ///br.financas.yahoo.com.
} 
gráfico de informação de volume em formato de barra. Conta, ainda, com indicadores técnicos, tais como, como $\mathrm{MACD}^{12} \mathrm{e}$ $\mathrm{MFI}^{13}$. O site apresenta gráficos desde 2000 . No entanto, só apresenta informações de fechamento dos ativos, ficando de fora informações como abertura, máximo, mínimo e a variação do dia selecionado. Também possui uma versão para dispositivos móveis, i.e., o Yahoo Finances.

O Terra Economia ${ }^{14}$ possui um gráfico no formato de linhas, possui alguns índices para estudo e apresenta o gráfico de volume do período selecionado. No entanto, essa ferramenta só apresenta informações em um período de cinco anos, seu gráfico é estático e não informa nada sobre abertura, máximo, mínimo e oscilação do dia selecionado. A Exame Brasil ${ }^{15}$ possui um gráfico interativo com a informação do fechamento do ativo, e outro gráfico para a quantidade de negociações desse ativo no período. A ferramenta conta ainda com a opção de tipo de gráfico - i.e. linha, OHLC e Vela -, seleção de períodos customizados e possui seis indicadores técnicos, sendo todos de médias móveis, apenas variando o tipo e a quantidade de dia. No entanto, essa ferramenta apresenta um período máximo de 10 anos e não conta com opção de alerta de preços.

O MarketWatch ${ }^{16}$ é uma ferramenta que fornece notícias, análises e dados sobre o mercado de ações. Possui gráfico interativo, gráficos de volume e quantidade de negociação. Porém seu gráfico interativo apenas provê informação de fechamento e mostra dados a partir de 2000. Ele não conta com a opção de seleção de um intervalo de data especifico, apenas fornece datas definidas para a visualização. Também conta com parcerias como o BigCharts.com para a análise gráfica, um simulador de mercado, o VirtualStockExchange.com e possui um aplicativo para os dispositivos móveis. O Bloomberg ${ }^{17}$ combina o mercado de ações com a análise financeira e de notícias. Não é um aplicativo estritamente dedicado às ações e carteiras, mas fornece informações suficientes para o investidor. Seu gráfico interativo mostra as informações de abertura, fechamento, mínima e máxima dos dias selecionados no período. Possui dois tipos de gráficos e conta com sete indicadores técnicos. Também possui gráfico de volume na forma de barra. No entanto, seu período máximo é limitado a cinco anos. O NinjaTrader ${ }^{18}$ é um software desktop que tem por objetivo oferecer informações e estudos técnicos para investidores com o perfil avançado. Trata-se de uma ferramenta bastante completa e complexa, com diversas opções de estudo, indicadores e algumas formas de visualização gráfica. Sua tecnologia gráfica usa a plataforma .NET. No entanto, sua utilização fica limitada a plataforma desktop.

Com base na análise das ferramentas relacionadas obtivemos conhecimento e identificamos necessidades básicas de ferramentas desse domínio. Cada solução prove informações de análises técnicas, como gráficos e dados de forma gratuita, porém

\footnotetext{
${ }^{12}$ Acrônimo de Moving Average Convergence Divergence, que é uma técnica que pode ser usada para revelar pontos de reversão de tendência do mercado.

${ }^{13}$ Acrônimoc de Índice de Fluxo Monetário, que é um oscilador calculado por um período de $n$-dias.

${ }^{14} \mathrm{http} / / /$ img.economia.terra.com.br/empresas/detalle.aspx.

${ }^{15} \mathrm{http} / / /$ exame.abril.com.br/mercados/cotacoes-bovespa.

${ }^{16} \mathrm{http}: / /$ www.marketwatch.com.

${ }^{17} \mathrm{http}: / /$ www.bloomberg.com.

${ }^{18} \mathrm{http}: / /$ www.ninjatrader.com.
}

além de possuir limites, algumas são pagas. Algumas fornecem informações de análises fundamentalistas, porém, também são pagas. A maioria das ferramentas empregam tecnologias limitadas ou obsoletas para geração de gráficos, o que pode impossibilitar a visualização em algumas plataformas como, por exemplo, mobile. Com isso nota-se a necessidade de uma ferramenta multiplataforma que permita a visualização das informações para apoiar investidores em, por exemplo, dispositivos móveis - e.g. tablets e smartphones - de forma responsivo.

Outro ponto importante foi a percepção de que a maioria das ferramentas apresentaram limitações no que tange ao período máximo da visualização do histórico do ativo, deixando ausente informações sobre todos os anos que o ativo está operando na bolsa de valores. Além disso, apenas algumas das ferramentas mencionadas apresentavam a funcionalidade de alertas por preço do ativo customizada de acordo com a necessidade do investidor, para os que desejam se manter informado do que está acontecendo no mercado, mas não dispõe de tempo para estar coletando essas informações, de forma esparsa, na Internet.

\section{CHRONOS AÇÕES}

O Chronos Ações ${ }^{19}$ é uma ferramenta que auxilia as pessoas que estão iniciando seus investimentos em mercado de ações e que não tem tempo de estar adquirindo informações sobre as ações diariamente. O Chronos Ações, também busca outras métricas e resultados de pré-processamento de dados para que essas informações sejam entregues de uma forma clara dos usuários. Também é possível visualizar informações dos ativos desde o início de sua negociação na bolsa de valores.

Com a utilização de novas tecnologias, é possível atingir uma gama maior de usuários, pois as ferramentas empregadas no desenvolvimento da ferramenta tem suporte em diversas plataformas. A ferramenta permite que o usuário cadastre alertas customizados, pois o mesmo apresenta várias formas de combinação, que após o usuário configurar, quando acontecer o evento mencionado por ele, será disparado um e-mail de notificação.

\subsection{Arquitetura e Tecnologias}

O principal pilar do sistema é uma base de dados que contém os dados brutos disponibilizados pela BM\&FBOVESPA, com informações dos pregões desde 1986. Essa base é alimentada diariamente, em dias de funcionamento da BM\&FBOVESPA, com dados dos pregões. O programa responsável por alimentar essa base é o Chronos Ações Robô, que é um programa em execução continua no servidor (24/7). O Chronos Ações Robô também é o responsável por disparar os alertas, efetuar préprocessamento de dados (para questões de otimização da busca no Chronos Ações Web), e atualização de informações em mídias sociais. As informações pré-processadas são usadas na aplicação web para visualização dos dados em formato de gráficos. Essas informações são armazenadas em outra base de dados, que apenas fornecem dados para a aplicação web.

19 Haja vista que a ideia norteadora do Chronos Ações (http://www.chronosacoes.com.br) é trabalhar com a análise técnica [12] cronológica - séries históricas - dos principais ativos que operam na bolsa de valores, a origem do nome da ferramenta remete ao Deus do tempo na mitologia grega (Chronos) e aos próprios ativos (Ações) que são negociadas na bolsa de valores. 


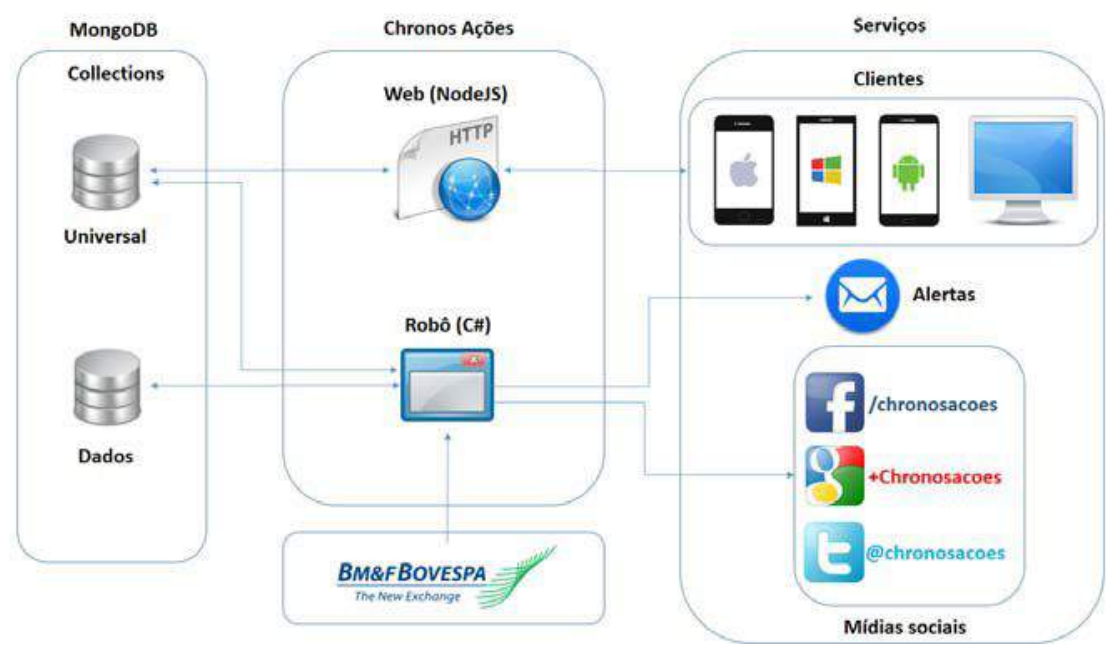

Figura 1. Arquitetura do Chronos Ações.

A aplicação web é a porta de entrada da ferramenta para os usuários, onde eles podem efetuar seu cadastro e usufruir dos serviços que o Chronos Ações oferece. A Figura 1 mostra a organização da estrutura envolvendo todos os componentes da ferramenta.

A base de dados está no formato $\operatorname{NoSQL}^{20}$ [7] e utiliza o MongoDB [8] como o gerenciador do banco de dados (BD). Os dados armazenados são orientados a documentos e a base de dados se divide em duas coleções ${ }^{21}$, i.e. Dados e Universal. A coleção Dados contém os dados extraídos diariamente dos servidores da BM\&FBOVESPA que fornece os dados em arquivo no formato por eles definido e, portanto, é necessário realizar um processamento para converter esses dados antes da utilização efetiva pelo Chronos Ações. Para começar a fornecer esses dados históricos, foi feito a importação inicial com dados desde 1986. Desse modo, hoje a coleção Dados conta com um volume de, aproximadamente, $10 \mathrm{~GB}$ de dados com cerca de 5,5 milhões de documentos armazenados.

O processo de atualização dessa base de dados é diário, com informações de todos os ativos que estão em operação. Diariamente, o site da BM\&FBOVESPA disponibiliza um arquivo com informações sobre os ativos e a disponibilização desse arquivo ocorre após o fechamento do pregão e antes da abertura do próximo pregão. O Chronos Ações Robô fica verificando junto ao sistema da BM\&FBOVESPA a disponibilidade desse arquivo após às $18 \mathrm{~h}$ - no fuso horário de Brasília, já que a BM\&FBOVESPA está na cidade de São Paulo em intervalos predefinidos (por padrão, a cada uma hora). Ao detectar a presença do arquivo, o programa efetua o download automaticamente, extrai as informações, salva no banco e préprocessa os dados para o Chronos Ações Web.

Diariamente, em dias de funcionamento da BM\&FBOVESPA, são processados cerca de 1.500 ativos e inseridos,

${ }^{20}$ NoSQL é o acrônimo de Not only SQL, que é um termo empregado para indicar banco de dados não relacionais.

${ }^{21}$ Uma coleção é um grupo de documentos. Em MongoDB um documento é análogo a uma tupla em BDs relacionais, e uma coleção pode ser análogo, com suas dividas restrições, a uma tabela. aproximadamente, mais 3.000 documentos no BD pela execução do robô. Para a melhoria da eficiência nas consultas dos usuários pela aplicação web, e evitar que o Chronos Ações Robô sobrecarregue o BD com consultas a fim de reduzir o desempenho da aplicação web, foi criado uma coleção separada, chamada de Universal. Essa coleção contém dados otimizados que foram preparados com os dados essenciais para a visualização de informações pelo usuário de forma rápida. Com isso é possível consultar dados de períodos muito grande - i.e. acima de 20 anos de dados - com uma boa eficiência, ou seja, em poucos segundos. Além disso, a coleção Universal conta com uma indexação por data dos dados e o código do ativo para otimizar a performance nas buscas.

Para o desenvolvimento da aplicação web foi utilizado o Google Chart, uma $\mathrm{API}^{22}$ de plotagem de gráfico, por apresentar diversas opções de gráficos e por possuir uma constância maior em relação a atualizações e suporte, além de conseguir ser visualizado sem a instalação de softwares terceiros como Java ou Flash. A aplicação web utiliza o NodeJS $\mathrm{S}^{23}$ como servidor de aplicação, por se tratar de uma tecnologia, relativamente, fácil de implementar e customizar. Essa tecnologia faz o uso de javascript do lado do servidor. Para algumas consultas, são feitas requisições via $\operatorname{REST}^{24}[10]$ para o servidor, utilizando a tecnologia AJAX [9].

O front-end é feito em HTML5, jQuery e CSS3, tecnologias atuais e que são utilizadas pela maioria das empresas no desenvolvimento de software. Para a customização rápida e prática do front-end, foi utilizado uma tecnologia chamada Bootstrap $^{25}$. Essa tecnologia permite que o design seja construído de forma rápida, organizada e responsiva, ou seja, se adaptam a diversos tamanho de telas. Ainda é oferecido diversos templates para serem incorporado ao projeto, agilizando ainda mais o tempo de desenvolvimento e com isso a produtividade. A forma de

22 No contexto de software, API (Application Programming Interface) é um conjunto de rotinas, protocolos e ferramentas para a construção de aplicações.

${ }^{23} \mathrm{http} / / /$ www.nodejs.org.

${ }^{24}$ Acrônimo de Representional State Transfer, que é um estilo de arquitetura de software.

${ }^{25} \mathrm{http}: / /$ www.getbootstrap.com. 
organização baseia-se em formação de linhas e colunas, onde as colunas podem ser de doze unidades, que podem ser quebrados em colunas menores, e cada coluna pode receber mais doze unidades e assim por diante. Para a elaboração da ferramenta, foram usados dois templates do Bootstrap, i.e., um template para as telas de login e cadastro e outro template para a tela principal e cadastro de alertas (Figura 3).

\subsection{O Robô (Chronos Ações Robô)}

O Chronos Ações Robô, em execução de forma contínua no servidor e que é utilizado apenas pelos administradores da ferramenta, é o programa responsável pelo controle das informações entre as coleções, pelo disparo de e-mails e informativos em mídias sociais. O programa foi desenvolvido em C\# [6]. Para efetuar todos os processos, o programa segue um fluxograma (Figura 2) que é disparado em intervalos predefinidos.

Caso ocorra algum problema de integridade de dados, esse programa conta com funcionalidades para corrigir problemas no BD. O monitoramento da integridade dos dias é realizado automaticamente pelo robô. Cada vez que o software é executado, o programa verifica os dias com status "pendente" para averiguar se houve algum problema naquele dia e, caso tenha ocorrido, o software tenta corrigir o problema automaticamente. Caso contrário, o dia é adicionado a uma lista de pendências, para a realização de intervenção manual desse determinado dia e, então, é disparado junto com o relatório diário por e-mail para os administradores do sistema junto com informações de logs.

\subsection{O Site (Chronos Ações Web)}

A aplicação web da ferramenta, utilizada pelos usuáriosinvestidores, tem como proposta oferecer a visualização de informações de uma forma fácil e ágil, para que investidores iniciantes consigam extrair informações relevantes para suas aplicações financeiras. Para que o usuário possa ter acesso a ferramenta, é necessário efetuar seu cadastro apenas colocando informações básicas, tais como, e-mail (usado caso o usuário deseje receber alertas, e para confirmar seu cadastro), senha, nome e sobrenome.

A página principal da ferramenta (Figura 3) apresenta um layout de fácil entendimento, e já apresenta para usuário informações sobre as maiores e menores variações ocorridas no último dia de que houve pregão sob a forma de tabelas.

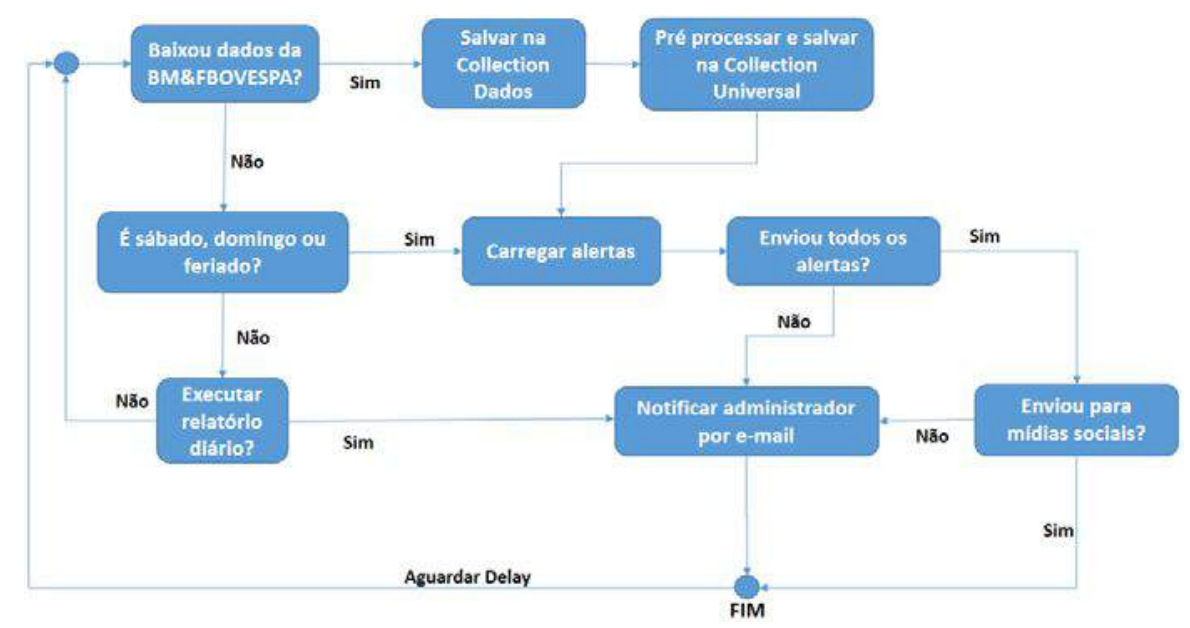

Figura 2. Fluxograma de funcionamento do Chronos Ações Robô.

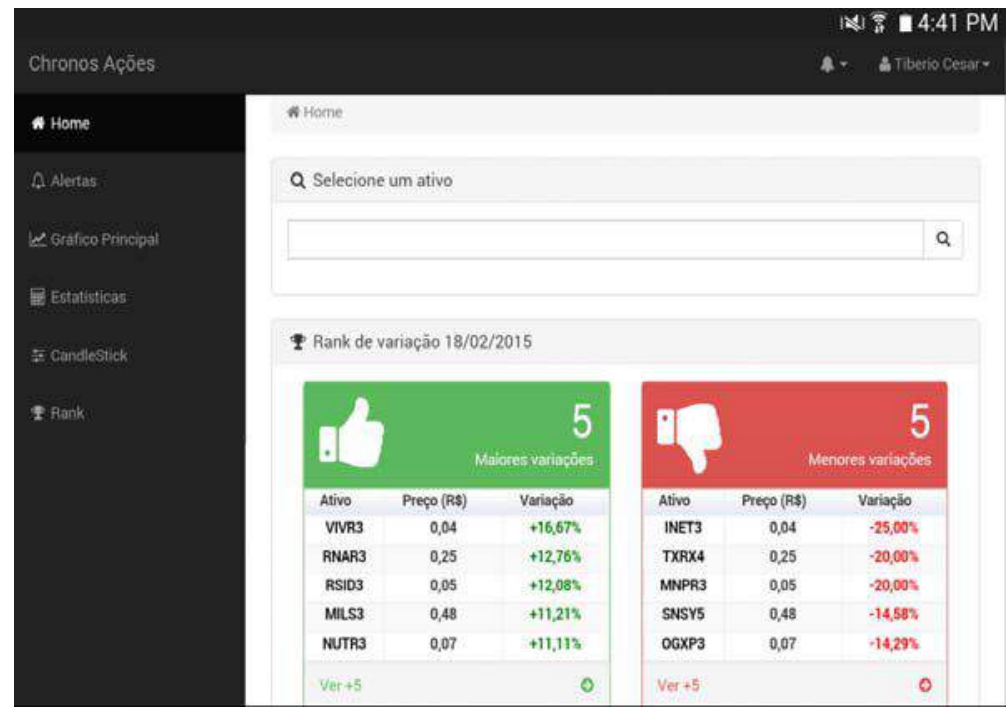

Figura 3. Tela principal do Chronos Ações Web. 
Acima dessas tabelas, existe o campo de busca principal do ativo que utiliza o componente de autocompletar para auxiliar a pesquisa do usuário pelo ativo desejado. Essa página principal contém uma barra lateral que permite que o usuário possa navegar de forma rápida dentro da página. O layout foi implementado com a preocupação de poder responder a qualquer tipo de tela, para poder redimensionar tanto os elementos em HTML da página i.e. menus, labels e barra lateral -, quanto os gráficos gerados pela API do Google. Para o redimensionamento dos gráficos foi necessário captar o evento de redimensionamento da tela, e após isso redesenhar os gráficos com os dados que se encontram no cliente, significando que o sistema não realiza consultas ao $\mathrm{BD}$ para recriar seus gráficos. O mesmo vale para consultas realizadas no período, que também são feitas no cliente, otimizando assim a velocidade de acesso à informação e evitando consultas desnecessárias ao BD. Com isso o usuário pode navegar em um histórico ou realizar consultas de maneira fluida, sem precisar esperar por informações serem carregadas.

A ferramenta suporta a visualização de informações desde o início do Plano Real, com a opção inicial de um gráfico no estilo linha (line chart). A Figura 4 apresenta um exemplo de gráfico desse estilo para as ações ordinárias do Banco do Brasil (código do ativo: BBAS3). Esse gráfico foi gerado com informações desde o primeiro dia de negociação dessa ação na bolsa de valores, ou seja, a quase 30 anos atrás (esse gráfico foi gerado pela ferramenta em, aproximadamente, cinco segundos). O gráfico permite a visualizações de diversas informações referentes a esse ativo ao longo desse período (16/MAR/1998 à 05/MAR/2015), tais como, valores de abertura, fechamento, mínimo, máximo e a variação diária, apenas posicionando o cursor do mouse por cima da data que se deseja visualizar essa informação.

A ferramenta permite que o usuário efetue filtros por períodos, não o limitando a períodos específicos, apesar da ferramenta também fornecer opções para um mês, três meses, seis meses, um ano, dois anos, cinco anos e o máximo (que corresponde a todo período de informações do ativo selecionado).

Dinamicamente, junto com a seleção do período, outras informações são carregadas para a visualização do usuário, como a quantidade de negociação diária no formato de barras, o gráfico que representa o volume diário do ativo selecionado no formato de área e as informações relativas a esse período, como o mínimo preço que o ativo atingiu durante o período e a sua data, o máximo valor e a sua data, o valor médio, o desvio padrão e o total de dias que o ativo operou na bolsa durante o intervalo. Os gráficos de volume e quantidade de negociação são importantes porque podem, junto ao gráfico de linha e o Candlestick, confirmar tendências de reversão no preço do papel, ou podem indicar uma situação de blefe, ao comparar a quantidade de negociação, o volume e a variação produzido no mesmo dia.

A ferramenta também possui uma funcionalidade bastante peculiar - não disponível, por exemplo, nas ferramentas relacionadas (Seção 2) -, que dá a variação em reais de cada dia no período determinado pelo usuário, e outro indicando quais as variações mais frequentes ocorrerem. Essas informações textuais e gráficas - são importantes para o investidor, pois quando o investidor for comprar ou vender seus papéis, poderá junto com a média, estimar uma variação para cima ou para baixo do que o ativo pode variar durante o dia e, assim, dá um lance mais preciso, ou seja, com uma maior probabilidade de acerto. Além de apresentar informações sobre a variação em reais diária, sobre o ativo selecionado durante o período determinado. Informações como a mínima variação que esse ativo operou em determinado dia, o máximo valor, o valor médio, e o desvio padrão (ou seja, a tendência que isso pode ocorrer).

O gráfico em forma de Candlestick (Figura 5), também é usado em quase todas as ferramentas, pois oferecem informações diárias em uma forma diferente. A maior vantagem da técnica reside na capacidade de gerar sinais antecipados de reversão (ou possibilidade de reversão ao investidor) [5]. Mas a visualização fica prejudicada quando o período é maior. Chronos Ações também possui o gráfico em forma de Candlestick, mas a sua visualização é mensal, e de navegação rápida para outros meses, caso deseje visualizar outro período. Geralmente a análise em Candlestick é utilizada por usuários com mais experiência, e essas análises não costumam ser de períodos longos.

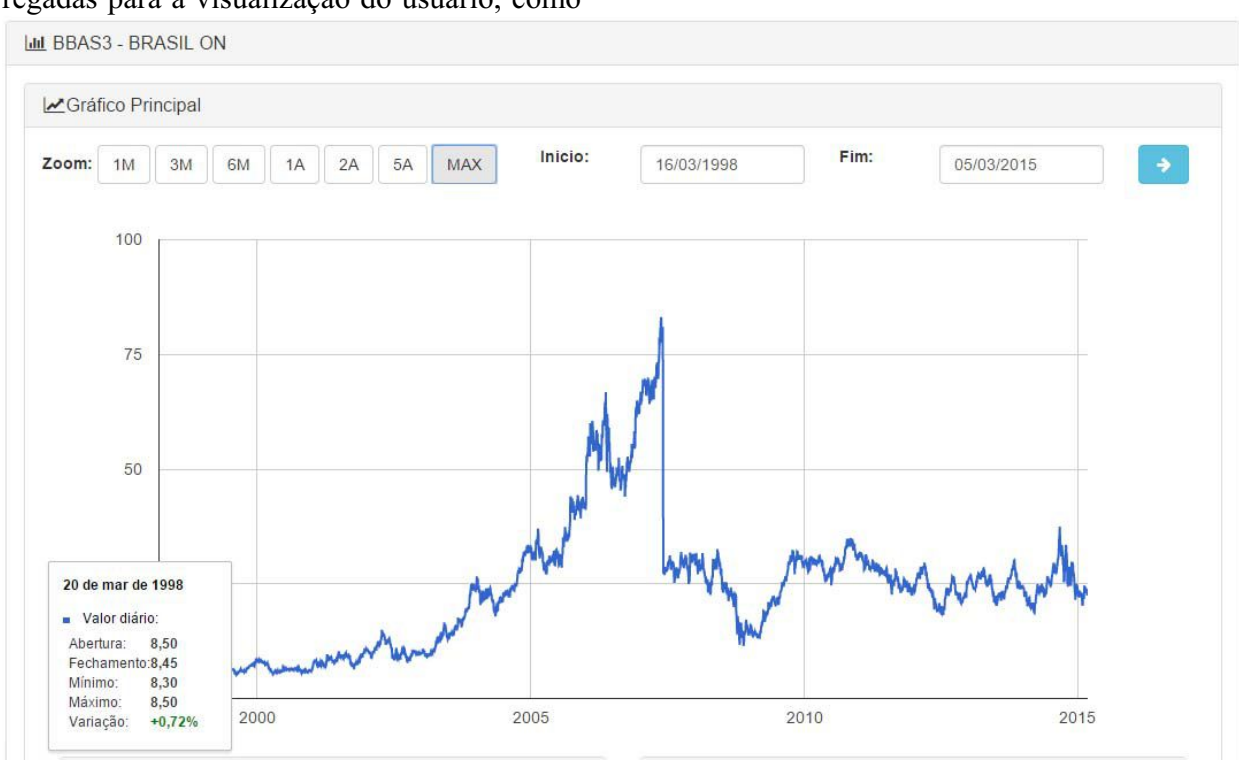

Figura 4. Gráfico principal da ação ordinária do Banco do Brasil (BBAS3) desde 1998. 


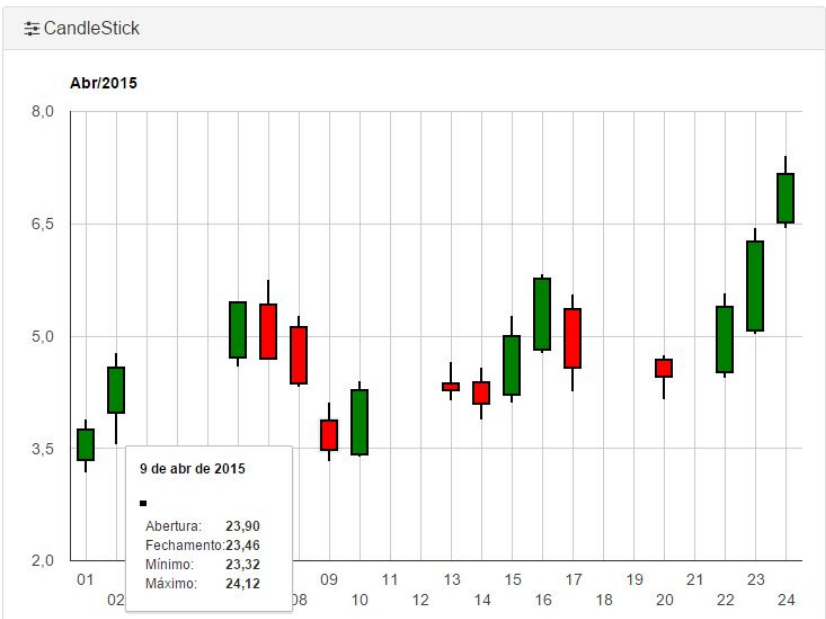

Figura 5. Gráfico do tipo Candestick apresentando um período de um mês.

A página principal ainda conta com um ranking que informa para o usuário os ativos que encerraram o último pregão com as maiores oscilações, e os que encerraram com os piores valores de oscilação. Inicialmente o ranking carrega com os cinco últimos valores, mas o usuário pode varrer toda a lista, sempre de cinco em cinco, clicando na opção "ver +5 ". Algumas ferramentas como a ADVFN e a BM\&FBOVESPA apresentam esquemas de ranking também, mas no caso da BM\&FBOVESPA, a ferramenta limita há apenas cinco ativos. $\mathrm{O}$ interessante de visualizar esse tipo de informação e poder enxergar possíveis oportunidades de compra/venda, fazendo com que o investidor possa ter mais opções de investimentos e poder diversificar a sua carteira.

Na página dos alertas (Figura 6), o usuário pode cadastrar alertas customizados pelos ativos, parâmetros, comandos e o valor desejado. A lista de ativos é composta pelos ativos que operam atualmente na bolsa de valores. Os parâmetros são as informações que a ferramenta provê, tais como, abertura, fechamento, máximo, mínimo e variação. A proposta é que assim que forem adicionadas novas métricas em versões futuras da ferramenta, essas métricas possam ser adicionadas a parte de parâmetros. Os comandos são opções de comparação que o usuário pode customizar com o valor que o investidor irá atribuir ao alerta. As opções de comando atualmente disponíveis são: maior, maior que, igual, menor e menor que.

A ferramenta permite um número ilimitado de cadastro de alertas por usuário que serão disparados para o e-mail cadastrado no sistema de acordo com a especificação inserida pelo usuário. A ferramenta apresenta duas listas de alertas, uma comporta os alertas que estão pendentes de envio, ou seja, não atingiram ainda a condição de disparo; e a outra lista apresenta os alertas que já foram enviados para o usuário, com a data e hora do envio.

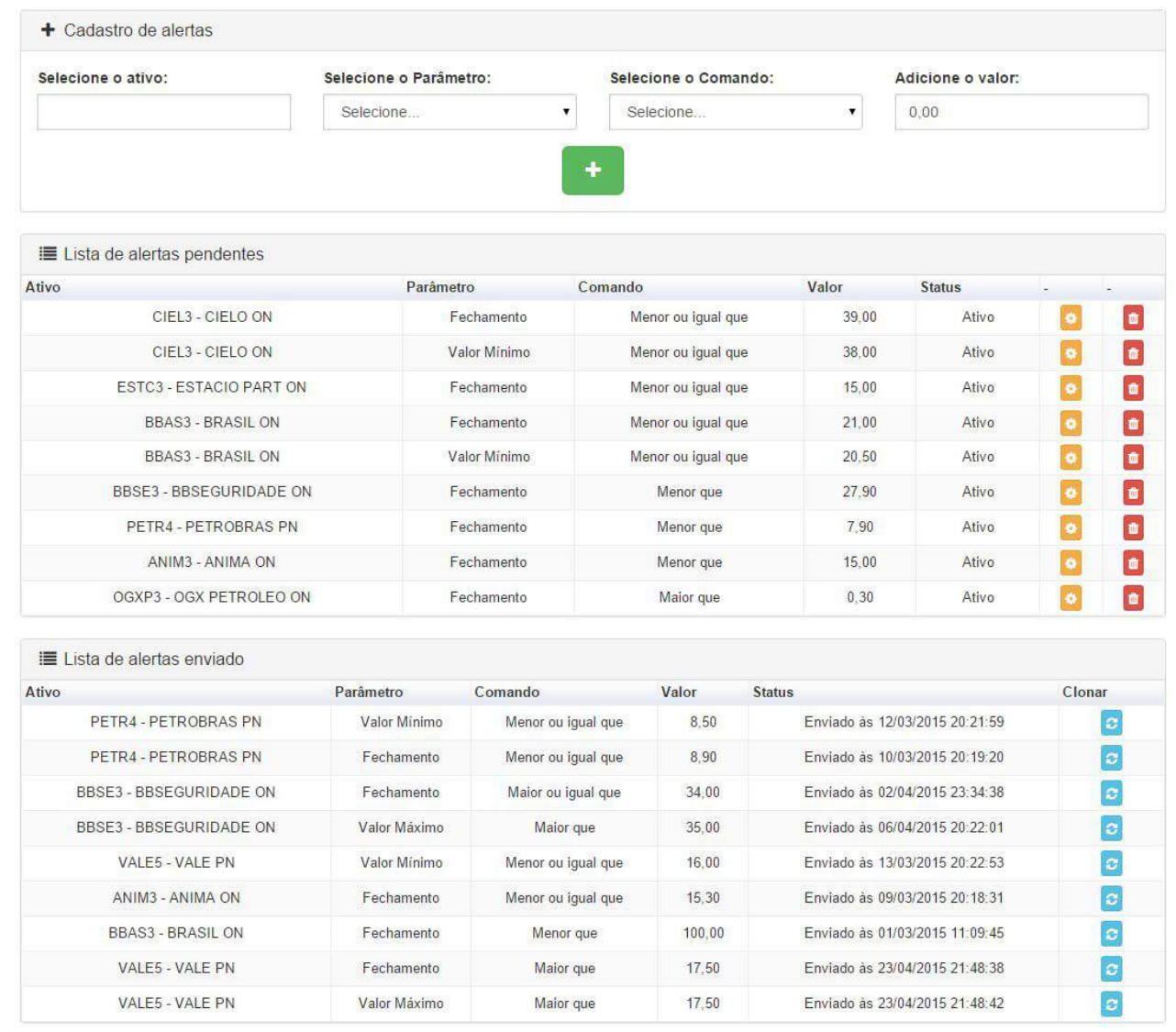

Figura 6. Tela do gerenciador de alertas. 
Nessa lista é possível "clonar" o alerta, que basicamente é fazer uma cópia com as mesmas configurações para a lista de alertas pendentes. A lista de alertas pendentes tem opções para alterar ou excluir um alerta já cadastrado.

\section{DISCUSSÃO}

Uma das grandes questões levantadas para a elaboração deste trabalho, além de fornecer dados aos investidores iniciantes, era justamente está provendo os dados com a ausência de limitações, que algumas ferramentas impõem como, por exemplo, fornecer dados de apenas os últimos cinco anos, não sendo possível visualizar dados anteriores. Este trabalho permite a visualização de todo o histórico possível de um determinado ativo, e a possível seleção de intervalo de períodos de uma forma rápida pelo usuário. Outra grande questão é a presença de alerta em poucas ferramentas, que pode vir a ajudar os investidores que não possuem tempo por estarem se atualizando de informações com frequência. $\mathrm{Na}$ prática, os alertas ajudam os investidores a sinalizar uma zona de potencial importância para ele, de acordo com as suas necessidades.

Algumas das ferramentas apresentadas nesse projeto apresentam tecnologias de construção de gráficos "antigas", que não são suportadas por algumas plataformas, como é o caso do Flash ou que precisam de software de terceiros instalados para poderem executar. O intuito foi desenvolver algo que independesse de plataforma e que não precisasse de instalação de software de terceiros para executar.

A ferramenta não fornece as informações de intraday, pois o foco desse trabalho foi fazer o uso de dados capturados ao final do dia, com o objetivo de montar os gráficos técnicos e criar tabelas com informações sobre os ativos. Caso optássemos por utilizar dados do intraday, esse volume cresceria de forma exponencial, podendo o BD chegar em alguns poucos meses na casa dos TeraBytes (TBs) de dados (atualmente o BD possui aproximadamente 10GB e com com cerca de 5,5 milhões de documentos).

Como forma de aprimoramento deste trabalho, podem ser incorporados a detecção de padrões relativos aos gráficos técnicos, e a aplicação de novas formas de gráficos para a visualização dessas informações. A sugestão é a introdução de técnicas de investidores mais experientes em investidores iniciantes, de uma forma fácil. Um dos exemplos é o uso de padrão em gráficos de CandleStick como o Harami, Doji, Martelo enforcado e Estrela da manhã [4,5]. Outra forma de aprimoramento é a criação de ferramentas que possibilitem fornecer informações sobre suporte e resistências, rompimentos, figuras de reversão associado a um ativo e novas opções de ranking voltadas a processamento das informações históricas, fazendo com que o investidor possa detectar tendências de forma mais rápida e tomar ações a fím de obter o máximo de lucro possível, ou então detectar novas possibilidades de diversificar sua carteira.

\section{CONCLUSÃO}

Neste trabalho apresentamos o Chronos Ações, uma ferramenta desenvolvida para apoiar investidores iniciantes da bolsa de valores BM\&FBOVESPA. A ferramenta foi implementada utilizando os mais novos paradigmas $\mathrm{e}$ tecnologias de desenvolvimento de software da atualidade. A ferramenta é multiplataforma e funciona no navegador de forma responsivo, inclusive os gráficos, tanto utilizando o navegador web de computadores desktop ou notebooks, bem como, de dispositivos móveis. A ferramenta permite a visualização completa do histórico do ativo, i.e., desde o primeiro dia de negociação do ativo na bolsa de valores e conta, ainda, com um serviço de alertas por e-mail.

Como trabalho futuros, sugerimos a incorporação de modelos de análises técnicas e o uso de alertas em dispositivos móveis. Também sugerimos a aquisição dos dados do intraday e o estudo dos dados coletados e armazenados diariamente para gerar estatísticas úteis para os investidores.

\section{AGRADECIMENTOS}

Este trabalho contou com o apoio da Fundação de Apoio à Pesquisa do Estado do Rio Grande do Norte (FAPERN) e do Grupo de Pesquisa em Artefatos Físicos de Interação (PAIRG) da Universidade Federal do Rio Grande do Norte (UFRN). Agradecemos, ainda, ao apoio do Núcleo de Inovação Tecnológica (NIT) da UFRN.

\section{REFERÊNCIAS}

[1] Portal do Investidor. Disponível em: $<$ http://www.portaldoinvestidor.gov.br>. Acesso em: 03 mar. 2015.

[2] Bolsa Financeira: O que são ações?. Disponível em: $<\mathrm{http}$ ://www.bolsafinanceira.com>. Acesso em: 03 mar. 2015.

[3] ITU: Statistics. Disponível em: $<$ http://www.itu.int/en/ITUD/Statistics/Pages/stat/default.aspx $>$. Acesso em: 03 mar. 2015.

[4] Dehner Junior, D. Análise Técnica. DVD. Rio de Janeiro: Suma Economia, 2010. P\&B.

[5] Debastiani, C.A. Candlestick: Um Método para Ampliar Lucros na Bolsa de Valores. Novatec, São Paulo, 2007.

[6] Stellman, A. e Greene, J. Use a Cabeça! C\#. 2. ed. Alta Books, 2010.

[7] Fowler, M. e Sadalage, P.J. NoSQL Essencial: Um Guia Conciso para o Mundo Emergente da Persistência Poliglota. Novatec, 2013.

[8] Chodorow, K. MongoDB: The Definitive Guide. 2. ed. Sebastopol, Califórnia: O'reilly, 2013.

[9] Riordan, R.M. Use a Cabeça! AJAX Profissional. Alta Books, 2009.

[10] Richardson, L. e Ruby, S. RESTful Web Services. Sebastopol, Califórnia: O'reilly, 2007.

[11] Glanso, F.R.C. Seminário Bolsa de Valores. Disponível em: $<$ http://www.ibb.unesp.br/Home/Graduacao/ProgramadeEdu cacaoTutorial-PET/bolsa_de_valores-laranja.pdf $>$. Acesso em: 05 mar. 2015.

[12] Hissa, M. Sobreviva na bolsa de valores: Um roteiro para acumular capital com ações e renda variável. Elsevier, Rio de Janeiro, 2008. 